\title{
EDUCACIÓN TÉCNICA Y REFORMA EDUCATIVA DURANTE LA «REVOLUCIÓN ARGENTINA» (1966-1973)
}

\author{
Technical education and educational reform during \\ the "Argentine Revolution" (1966-1973)
}

\section{Gabriela Andrea D'Ascanio ${ }^{\alpha}$}

Fecha de recepción: 06/07/2021 • Fecha de aceptación: 15/09/2021

Resumen. En la Argentina, los gobiernos autoritarios y desarrollistas de la «Revolución argentina», que ocuparon el poder en el período 1966-1973, concibieron a la educación como una inversión rentable, proveedora de los recursos humanos necesarios para el desarrollo económico, desde distintas perspectivas: espirituales, integrales y pragmáticas. En este trabajo se indaga sobre las transformaciones, permanencias y alcances de dichas nociones en los discursos y políticas vinculados a la educación técnica. Se describen las ideas rectoras que sostuvieron los gobernantes y funcionarios del sistema educativo con respecto a esta modalidad y el papel que le atribuyeron en el proceso de modernización que intentaron gestar. En particular, se reconstruye el vínculo conflictivo entre la Reforma educativa emprendida a finales de la década de los sesenta y el Consejo Nacional de Educación Técnica (CONET), órgano de gobierno del subsistema de enseñanza técnica. Focalizando en este último, para finalizar, se tratan los cambios institucionales, la oferta educativa y las limitaciones que afectaron la expansión de la educación con fines profesionales, tanto en el nivel secundario, como en la capacitación de jóvenes y adultos, y en la formación de instructores. El abordaje metodológico empleado es el de la historia política e institucional y las fuentes utilizadas son de diversa procedencia: oficiales, periodísticas y legislativas.

Palabras clave: Educación técnica; Educación y trabajo; Reforma educativa; CONET.

\footnotetext{
${ }^{\alpha}$ Instituto Rosario de Investigaciones en Ciencias de la Educación - Consejo Nacional de Investigaciones Científicas y Técnicas / Universidad Nacional de Rosario. Ocampo y Esmeralda, Rosario, C.P. 2000 - Santa Fe, Argentina. gabidascanio@gmail.com (D) https://orcid.org/0000-0001-9809-3820
}

Cómo citar este artículo: D’Ascanio, Gabriela Andrea. «Educación técnica y reforma educativa durante la "Revolución argentina"»(1966-1973)». Historia y Memoria de la Educación 15 (2022): $325-355$ 
Abstract. In Argentina, the developmentalist and authoritarian governments of the "Argentine Revolution", which were in power during the 1966-1973 period, conceived of education as a profitable investment, something which could provide the human resources necessary for economic development, from different perspectives: spiritual, comprehensive, and pragmatic. In this work we examine the transformations, continuities and scope of those notions as expressed in the discourses and policies linked to technical education. We also describe the leading ideas advocated by governors and officials in relation to this modality of teaching along with the role these ideas played in the modernization process they we trying to promote. Specifically, we reconstruct the controversial link between the Education Reform started in the late 1960s and the National Council for Technical Education (Consejo Nacional de Educación Técnica - CONET), a government body pertaining to the technical national education subsystem. Finally, we focus on said Board, institutional changes, educational offer, and the restrictions affecting the technical education expansion at the secondary level, youth and adults training and the instructors' formation. The methodological approach used is that of the Political and Institutional History and the sources are of different origins: official, journalistic, and legislative.

Keywords: Technical education; Education and work; Education reform; CONET.

\section{INTRODUCCIÓN}

Los gobiernos de facto sostenidos por las Fuerzas Armadas durante el período 1966-1973, constituyeron sucesivas fases de la autodenominada «Revolución argentina». Con variantes en las políticas sectoriales, pero unidad en cuanto a su plan de desarrollo, la doctrina de la seguridad nacional se impuso como defensa de la soberanía y también como control de las ideas y actores que pudieran afectar el orden institucional vigente. Las vías del crecimiento económico, la planificación, la formación de recursos humanos y la racionalización del sistema educativo fueron preocupaciones constantes del elenco gobernante, aunque las políticas económicas recesivas y discontinuadas afectaron su concreción. ${ }^{1}$ En el plano discursivo, los funcionarios destacaron con asiduidad

\footnotetext{
1 Marcelo Cavarozzi, «Autoritarismo y democracia, 1955-1983», en La sociedad y el estado en el desarrollo de la Argentina moderna, comp. Torcuato S. Di Tella y Cristina Lucchini (Bs. As.: Biblios, 1999), 201-248; Ronaldo Munck, «Movimiento obrero, economía y política en Argentina: 1955-1985», Estudios Sociológicos, vol. 13, n. 5 (1987): 87-109; Liliana de Riz, La política en suspenso 1966/1976 (Bs. As.: Paidós, 2000); Pablo de San Román, «Los militares y la idea de progreso: la utopía modernizadora de la Revolución argentina (1966-1971)», Documentos de Trabajo IELAT, n. ${ }^{31}$ (2011): 1-32;
} 
las potencialidades de la educación formal, y de la educación técnica en particular, como dinamizadoras de la modernización tecnológica, económica y social, cuya meta era lograr una industrialización pesada, un deseo incumplido en las dos décadas anteriores. ${ }^{2}$ De tal manera, el objetivo de este artículo es reconstruir los discursos que distintos funcionarios nacionales sostenían acerca de la educación técnica, las propuestas de inserción de la modalidad en la Reforma educativa inconclusa de fines de la década de los sesenta y las acciones del Consejo Nacional de Educación Técnica (CONET). Para ello se describen las ideas sostenidas por los principales funcionarios del sistema educativo que vinculaban la educación técnica con el desarrollo nacional, se indaga en la ampliación y actualización de la oferta de nivel medio - o su equivalente- dependiente del CONET y se analizan los límites en la ejecución de las políticas de la Reforma proyectada.

El CONET fue creado en 1959. Debía dirigir y administrar los establecimientos de educación técnica y formación profesional que habían dependido de la Comisión nacional de orientación y aprendizaje profesional (CNAOP), así como del Ministerio de Cultura y Educación de la nación. Su misión fue la de «educar integralmente a la juventud y lograr la capacitación técnico profesional de sus educandos».3 A mediados de la década de los sesenta se llevó adelante una unificación institucional y curricular de todas las escuelas medias que dependían del CONET, bajo la denominación de escuelas nacionales de educación técnica (ENET), suprimiéndose las escuelas-fábricas y las escuelas industriales de la nación. ${ }^{4}$

\footnotetext{
Miguel A. Taroncher Padilla, «El proceso de inestabilidad político institucional en la Argentina: el golpe de estado de 1966 y algunos aspectos de la opinión pública», Estudios Ibero-Americanos, vol. 38, n. 1 (2012): 45-61; Adrián Ascolani y Talía Gutiérrez, «Introducción», en Agro y política en Argentina. Tomo III. Desarrollismo, reforma agraria y contrarrevolución, 1955-1976, coord. Adrián Ascolani y Talía Gutiérrez (Bs. As.: Ciccus, 2020), 3-17.

${ }^{2}$ Martín Fiszebein, «Crecimiento desbalanceado y estructura productiva desequilibrada en Argentina (1945-1976): problemas e ideas del modelo industrial en retrospectiva», en Estudios sobre la industria argentina, comp. Marcelo Rougier (Bs. As.: Lenguaje claro, 2013), 49-74; Claudio Bellini, "Controversias y oscilaciones de la política industrial: de Perón a Frondizi», en Estudios sobre la industria argentina, comp. Marcelo Rougier (Bs. As.: Lenguaje claro, 2013), 117-162.

3 Boletín Oficial, «Ley N. ${ }^{\circ}$ 15240/59», año LXVII, n. 19.055 (1959).

4 Pablo Pineau, «La vergüenza de haber sido y el dolor de ya no ser. Los avatares de la educación técnica entre 1955 y 1983", en Dictaduras y utopías en la historia reciente de la educación argentina (1955-1983), dir. Adriana Puiggrós (Bs. As.: Galerna, 1997), 379-402.
} 
La estructura curricular de nivel medio destinada a varones que ofrecía el CONET se organizaba en dos ciclos de tres años cada uno. El primero era común a todas las especialidades del ciclo superior y propendía tanto a la formación integral del educando como al contacto directo con actividades productivas y laborales. Tras su finalización, el alumno podía optar por el «curso de término» o por el ciclo superior. En el primer caso, obtenía el título de auxiliar técnico en una especialidad dado que el plan de estudios enfatizaba en la cultura profesional con aplicaciones prácticas, para formar un operario calificado. El ciclo superior consistía en un complemento teórico-científico que permitía adquirir una especialización para conducir el proceso laboral y el título de técnico.

El organismo también sostenía otras propuestas de enseñanza destinadas a egresados del nivel primario que presentaban equivalencias con el ciclo básico del nivel medio: los cursos nocturnos de capacitación de operarios, destinados a obreros, otorgaban certificaciones de aptitud profesional y sostenían equivalencias con el ciclo básico nocturno; el ciclo de profesiones femeninas se prolongaba por tres años, tenía equivalencias con el ciclo básico de doble escolaridad y se articulaba verticalmente con cursos técnicos y prácticos que también dependían del CONET. Estos se prolongaban por uno o dos años y eran terminales.

Además, el organismo ofrecía cursos terminales como los de formación profesional acelerada, destinados a jóvenes y adultos sin oficios que no poseían la escolaridad primaria concluida y otorgaban una constancia de adiestramiento en la especialidad cursada; el ciclo de manualidades femeninas que se extendía por dos años y otorgaba un certificado de competencia; y las misiones monotécnicas y de cultura rural y doméstica, que sostenían propuestas de enseñanza diferenciadas para varones y mujeres, se prolongaban por dos años y no exigían examen de ingreso. Además para técnicos, docentes y directivos de la modalidad ofrecía cursos de especialización y perfeccionamiento.

En un breve estado del arte, respecto de la política educativa de la Revolución argentina, hubo algunos textos coetáneos a los fenómenos estudiados que siguen siendo valiosos. La obra colectiva compilada por Villaverde ${ }^{5}$

\footnotetext{
5 Aníbal Villaverde, «La escuela intermedia en la accidentada evolución de la reforma educativa», en La Escuela Intermedia en debate, ed. Alfredo Bravo y Aníbal Villaverde (Bs. As.: Ed. Humanitas, 1971), 231-260.
} 
se ocupó de analizar el proyecto de reforma que creaba el nivel intermedio - entre el primario y el secundario- describiendo los elementos estructurales y testimoniando las posiciones de los actores educativos. En algunos artículos de Tedesco ${ }^{6}$ se hizo más visible la influencia de la teoría de la dependencia que cuestionaba, desde una perspectiva que combinaba el marxismo con el estructural-funcionalismo, las inequidades de la oferta educativa. Con estas perspectivas sociológicas surgió un primer texto sobre la evolución específica de la enseñanza técnica durante el gobierno justicialista, escrito por Wiñar, ${ }^{7}$ que proporcionó elementos para conectar la educación técnica con la industrialización y el mercado de trabajo. Desde un planteo descriptivo, Martínez $\mathrm{Paz}^{8}$ sintetizó las propuestas de la Organización de los Estados Americanos (OEA) y la Organización de las Naciones Unidas para la Educación, la Ciencia y la Cultura (UNESCO) sobre la concepción de la educación como una inversión, siendo uno de los motores principales para el cambio social y otorgando al Estado un rol fundamental en el planeamiento integral del sistema educativo. Retomando las concepciones de la teoría de la dependencia, Puiggrós ${ }^{9}$ analizó el imperialismo norteamericano en América Latina, mostrando la gran injerencia que tuvo en muchos países - aunque no en Argentina- a partir de la firma de la Carta de Punta del Este, en la cual se constituyó la Alianza para el Progreso. Un tratamiento más actualizado de estos asuntos ha sido abordado por C. Suasnábar ${ }^{10}$ que retomó la discusión sobre desarrollismo y educación, a través del análisis de las obras de intelectuales vinculados a entidades internacionales como la Comisión Económica para América Latina y el Caribe (CEPAL) y la UNESCO, mostrando el abanico de posiciones sobre la cuestión. Reveló que las ideas desarrollistas generadas por la CEPAL y las derivadas de la teoría del

\footnotetext{
6 Juan Carlos Tedesco, Industrialización y Educación en Argentina (UNESCO, Programa Desarrollo y Educación en América Latina y el Caribe, 1977).

7 David Wiñar, Educación Técnica y evolución social en Argentina (Bs. As: Comisión Económica para América Latina, 1981).

${ }^{8}$ Fernando Martínez Paz, El Sistema Educativo Nacional. Formación. Desarrollo. Crisis (Córdoba: UNC, 1980).

9 Adriana Puiggrós, Imperialismo y Educación en América Latina (México: Nueva Imagen, 1980).

${ }^{10}$ Claudio Suasnábar, Intelectuales, exilios y educación. Producción intelectual e innovaciones teóricas en educación durante la última dictadura (Rosario: ProHistoria, 2013). Claudio Suasnábar, «Desarrollismo, sociología científica y planeamiento de la educación: el debate intelectual de los sesenta», en Universidad e Intelectuales. Educación y política en la Argentina (1955-1976), ed. Claudio Suasnábar (Bs. As.: Edit. FLACSO/Manantial, 2004), 29-46.
} 
capital humano adquirieron un carácter dominante en los debates pedagógicos. En esta línea puede situarse un trabajo de Romina De Luca ${ }^{11}$ en el que analizó las recomendaciones de descentralización del sistema educativo realizadas por la Comisión Nacional de Desarrollo (CONADE).

En la década de los noventa fueron escritos otros textos referidos a la educación técnica nacional. El de Pineau ${ }^{12}$ sobre los dos primeros gobiernos peronistas es un antecedente valioso porque recuperó la investigación de Wiñar y le aportó otros indicadores empíricos que permitieron ver la complejidad política de su desarrollo institucional, focalizando en la aparición y funcionamiento de las escuelas fábricas. En otro artículo $^{13}$ este autor estudió las lecturas e interpretaciones que suscitó el subsistema de educación técnica constituido en las décadas de los cuarenta y de los cincuenta. En las dos últimas décadas hubo una tendencia al estudio de la educación técnica en períodos largos de tiempo. Esto se percibe en el artículo de Pineau ${ }^{14}$ que reconstruyó las reformulaciones de la relación educación-trabajo en el período 1955-1983 y tomó como objeto de estudio el CONET, su legislación, oferta educacional y cambios curriculares. Más recientemente, la publicación de Sosa ${ }^{15}$ trazó el vínculo con el contexto económico-productivo, desde la década de los treinta hasta el gobierno kirchnerista, abordando la demanda de mano de obra calificada durante la etapa desarrollista. Por su parte, Gallart, ${ }^{16}$ abordó la evolución cuantitativa y cualitativa de la modalidad a lo largo del siglo XX. Un trabajo específico sobre la educación técnica durante la Revolución argentina es el de Bonavena, ${ }^{17}$ que describió la lucha estudiantil ante

\footnotetext{
${ }^{11}$ Romina de Luca, «La Reforma educativa de Onganía. El tercer momento de una estrategia», $R a$ zón y Revolución, n. ${ }^{\circ} 15$ (2006): 165-182.

12 Pablo Pineau, Sindicatos, estado y educación técnica (1936-1968) (Bs. As.: CEAL, 1991).

${ }_{13}$ Pablo Pineau, «De zoológicos y carnavales: las interpretaciones sobre la Universidad Obrera», en Estudios de Historia de la Educación durante el Primer Peronismo (1943-1955), dir. Héctor Cucuzza (Bs. As.: Libros del Riel, 1997), 205-228.

${ }^{14}$ Pablo Pineau, «La vergüenza de haber sido».

15 Mariana Sosa, «Desarrollo industrial y educación técnica: una estrecha relación. El caso Argentino», Revista Latino-Americana de Historia vol. 5, n. 15 (2016): 194-195.
}

${ }^{16}$ María Antonia Gallart, La escuela técnica industrial: un modelo para armar (Montevideo: OIT/ Cinterfor, 2006).

17 Pablo Bonavena, «La lucha de los estudiantes de las Escuelas Técnicas contra la Ley Fantasma», X Jornadas de Sociología, Facultad de Ciencias Sociales, Universidad de Buenos Aires (2013). http:// www.aacademica.org/000-038/301 
la posible sanción, en la provincia de Buenos Aires, de una ley que restringía el alcance de los títulos otorgados por el CONET a los técnicos en construcción y los ponía en una posición subordinada respecto a la de los ingenieros.

Otros textos que se ocuparon de la estructura y los funcionarios del sistema educativo del período 1966-1973 también aportan elementos para comprender el desarrollo de la educación técnica y la acción estatal para reformar el sistema educativo. Un análisis de las autoridades del Ministerio de Educación de la nación es el de Laura Rodríguez, ${ }^{18}$ quien reconstruyó sus filiaciones ideológicas y religiosas y también trató la reforma educacional propuesta, advirtiendo que combinó elementos católicos, elitistas, privatistas y desarrollistas. Los trabajos de Natalia García ${ }^{19}$ y de Liliana Aguiar de Zapiola ${ }^{20}$ revelaron, respectivamente, cómo las provincias de Santa Fe y Córdoba fueron precursoras en la introducción del nivel intermedio y de la formación docente en el nivel superior.

\section{REFORMA EDUCATIVA Y FORMACIÓN DE RECURSOS HUMANOS}

En 1968 el crecimiento experimentado por las matrículas de las modalidades agropecuarias e industriales desde 1964 era significativo ya que representaba respectivamente la suba del 50\% y del $14 \%$ del alumnado inscripto en relación a los años previos. Sin embargo el volumen del estudiantado continuaba considerándose insuficiente dado que no se había alterado la distribución desigual de la matrícula por modalidades. En el mismo período los estudiantes de las escuelas de comercio habían aumentado un $47 \%$, los de las escuelas normales un $46 \%$ y los de los colegios nacionales un 16\%. La concentración del 80,8\% de la matrícula en estos últimos establecimientos era reconocida como un problema para el desarrollo socio-económico del país y era correlativa a la cantidad de

\footnotetext{
${ }^{18}$ Laura Rodríguez, «Los católicos desarrollistas en Argentina. Educación y planeamiento en los años de 1960», Diálogos, v. 17, n. ${ }^{\circ} 1$ (2013): 155-184. http://dx.doi.org/10.4025/dialogos.v17i1.723

${ }_{19}$ Natalia García, «Visiones clandestinas, prácticas autoritarias y reforma educativa en Santa Fe (Argentina, 1966-1973)», Espacio, Tiempo y Educación, vol. 5, n. 1 (2018): 159-180. doi: http://dx.doi. org/10.14516/ete.202

${ }^{20}$ Liliana Aguiar, Pilar Castiñeira y M. del Cármen Orrico, «La formación docente en contextos de reformas. Procesos histórico-políticos en la Jurisdicción Córdoba», Cuadernos de Educación. La Educación como Espacio Público, año 2, n. ${ }^{\circ} 2$ (2002): 51-63.
} 
establecimientos: en 1966, en la órbita nacional, existían 218 ENET, diez escuelas agropecuarias, 241 ciclos básicos de bachilleratos, 169 establecimientos normales y 246 comerciales. ${ }^{21} \mathrm{El}$ incremento de la producción de bienes manufacturados y primarios —según gobernantes, funcionarios y entidades corporativas- exigía el aumento del número de escolares de las escuelas técnicas industriales, que representaba un 17,8\% de los alumnos secundarios, y de las escuelas técnicas agropecuarias, el cual se reducía al 1,6\%.22 En este sentido se orientaban algunos de los propósitos generales del Acta de la Revolución argentina: aspiraban a «consolidar los valores espirituales y morales; elevar el nivel cultural, educacional, científico y técnico; eliminar las causas [...] del estancamiento económico; alcanzar adecuadas relaciones laborales $[\ldots] » ; 23$ racionalizar la estructura de gobierno y la burocracia del Estado.

El presidente de facto Juan Carlos Onganía, que gobernó hasta el 8 de junio de 1970, proclamó interés por contribuir a la convergencia entre la política educativa y el desarrollo económico. La educación debía reorganizarse en función del progreso económico, siendo que le correspondía formar los recursos humanos requeridos por el mercado ocupacional. En el II Seminario iberoamericano de enseñanzas técnicas, que tuvo lugar en Buenos Aires, Onganía reconoció la existencia de un desencuentro entre los requerimientos del proceso de industrialización y la enseñanza, ponderó a la enseñanza técnica como el instrumento adecuado para el desarrollo de Latinoamérica y enfatizó en que la formación de técnicos debía ser un objetivo fundamental del Estado. ${ }^{24}$ Por su parte el secretario de estado de cultura y educación, José Mariano Astigueta (8/6/1967-16/6/1969), concebía al desarrollo desde una perspectiva espiritual y material. Se trataba de una voluntad universal de crecimiento propia del espíritu de todos los miembros de la civilización occidental y cristiana, que la educación debía «encausar» hacia un proyecto económico predefinido. La educación, en consecuencia,

\footnotetext{
${ }^{21}$ Ministerio de Cultura y Educación, «Establecimientos-alumnos-docentes. Años 1963-1972. Por dependencia y repartición. Educación pre-primaria, educación primaria, educación media, educación superior, educación parasistemática» Departamento de estadística (1973).

22 Pedro J. Cristiá, «La enseñanza agropecuaria en el país y sus prioridades», La Tierra, 21/01/1968.

${ }_{23}$ Secretaría de Estado de Gobierno, «Textos revolucionarios. Acta de la Revolución argentina con sus anexos», 1966, p. 25.

${ }^{24}$ Laura Rodríguez, «Los católicos desarrollistas».
} 
debía ser especialmente considerada en cualquier plan de desarrollo. Para el funcionario el país estaba en pleno desarrollo, lo cual exigía impulsar la formación de técnicos y de mano de obra capacitada y renovar las estructuras y los planes de estudio de la modalidad técnica vinculándolos con los sectores productivos de la industria, el agro y el comercio. ${ }^{25}$

El CONADE le atribuyó al CONET la responsabilidad de ser el «productor de recursos humanos aptos para lograr el desarrollo nacional» ${ }^{26}$ concebía a la educación técnica como una inversión y la presentaba como garantía del desarrollo económico. La centralidad que se otorgaba a la educación técnica en el desarrollo nacional era asumida también por las autoridades del CONET. En sus informes hacían explícito que partían del supuesto de que del alcance y extensión del nivel medio y técnico dependía el grado de desarrollo del país, de modo que la formación de técnicos constituía una meta relevante. ${ }^{27}$ En este sentido existía una correspondencia entre el desarrollo individual y social. Aseguraban que la educación técnica, por una parte, debía favorecer al desarrollo individual «a través de la adquisición de conocimientos tecnológicos, prácticos, con integración de la cultura general, sentido de responsabilidad e iniciativa creadora, que lo habilite para ampliar la capacidad productiva y satisfacer sus necesidades económicas» y, por otra, adaptarse y contribuir al bienestar colectivo. ${ }^{28}$ Similar perspectiva fue sostenida un año más tarde por el ministro del interior, Guillermo A. Borda, y por el subsecretario del Ministerio de Educación de la nación, Juan Rafael Amadeo Lerena. El ministro sostenía que la prosperidad económica era efímera si no se sostenía en el desarrollo político, cultural y moral. Ambos coincidían en que la educación debía alcanzar a las mayorías y poner al país en la avanzada de la ciencia y la técnica, siendo fundamental la descentralización de la administración escolar y la adaptación

\footnotetext{
${ }_{25}$ Oficina de educación iberoamericana, «II Seminario iberoamericano de enseñanzas técnicas. Discursos pronunciados en la solemne sesión de apertura», 1967. Centro nacional de información y documentación educativa (CeNDIE).

${ }^{26}$ CONET, «Algunas consideraciones sobre las actividades más importantes del Consejo nacional de educación técnica y su evolución prevista. Informe presentado para el II Seminario iberoamericano de enseñanzas técnicas. Secretaría de Estado de Cultura y Educación», 1967. CeNDIE.

27 Secretaría de Estado de Cultura y Educación, «3. ${ }^{a}$ Reunión nacional de ministros de educación. Informe final», 1968. CeNDIE.

${ }^{28}$ CONET, «Algunas consideraciones sobre».
} 
cuantitativa y cualitativa del sistema educativo para que proporcionase recursos humanos, respetando las singularidades personales. ${ }^{29}$

La idea de educación para el desarrollo se cimentaba tanto sobre una perspectiva de orden técnico y económico, como espiritual. En esa combinación de elementos discursivos, la concepción filosófica del trabajo funcionaba como variable articuladora de sentidos. El trabajo era presentado como un vehículo de autoperfeccionamiento personal mediante el cual se contribuía al progreso de la civilización. El ejercicio de cualquier actividad laboral constituía un medio para adquirir la plena personalidad; actualizar las potencialidades del hombre y perfeccionar sus facultades. El Estado debía «adecuar la educación en todos sus niveles al proceso de industrialización y sus requerimientos», ${ }^{30}$ proporcionando una formación integral, para una eficiente y armónica participación en la economía y en la sociedad.

Conforme a este marco de pensamiento se fue gestando una agenda de transformación educativa. En 1968, la Oficina sectorial de desarrollo «educación» formuló el Proyecto de reforma del sistema educativo argentino y se constituyó una comisión para pautar las bases de una ley orgánica de educación. Los documentos producidos debían ser analizados por los ministros de educación de la nación y de las provincias. ${ }^{31}$ Este proyecto introducía una modificación estructural en el sistema y proponía la extensión de la escolaridad obligatoria a nueve años, integrada por dos ciclos: el elemental, de cinco años, y el intermedio, de cuatro años. A esta «educación general básica» le seguía el ciclo medio de tres años no obligatorios. Los dos últimos años del ciclo intermedio ofrecerían variadas oportunidades de iniciación vocacional y de trabajo manual. Se postulaba que, de acuerdo con sus aptitudes, el egresado podría ingresar al sistema productivo o proseguir estudios superiores. Uno de los mentores de la Reforma, Gustavo Cirigliano, postulaba que la «formación práctica cursada en talleres según las orientaciones, aumentaría

\footnotetext{
${ }^{29}$ Secretaría de Estado de Cultura y Educación, «3. ${ }^{\text {a }}$ Reunión nacional de ministros de educación. Informe final», 1968. CeNDIE.

30 Secretaría de Estado de Cultura y Educación, «3. ${ }^{a}$ Reunión nacional», p. 45.

31 Ministerio de Cultura y Educación, «Crease una Comisión para elaborar anteproyecto de Ley de Educación. Resolución N. ${ }^{\circ} 231 »$, Boletín de comunicaciones, XIV, n. ${ }^{\circ} 4$ (1968). CeNDIE; Secretaría de Estado de Cultura y Educación, «3. ${ }^{\text {a }}$ Reunión nacional».
} 
la calidad de los recursos humanos».32 Respecto al ciclo medio se planteaba que los dos primeros años serían comunes mientras que el último adquiría dos orientaciones: técnico profesional (comercial, técnica, artística y agrícola) y científico humanista (ciencias físico matemáticas y humanidades). En ambas habría capacitaciones teóricas y prácticas, sistemáticas y específicas en función de los intereses y aptitudes de los alumnos, que prepararían para continuar estudios superiores e integrarse al mercado de trabajo. ${ }^{33}$

El ministro Dardo Pérez Guilhou (16/6/1969-8/6/1970), sucesor de Astigueta, postulaba que para que la enseñanza sirviera al país debía seguirse la agenda trazada por la Oficina sectorial de desarrollo, ${ }^{34}$ aumentar el presupuesto de la educación técnica y modernizar el sistema administrativo y financiero. ${ }^{35}$ El subsecretario de educación, Emilio Mignone, coincidía en era necesario aumentar los años de escolaridad, introducir cambios en los contenidos y metodologías de enseñanza y centrar la atención en la capacitación profesional dado que constituía el factor más importante para acelerar el desarrollo. El consultor del Ministerio de Cultura y Educación, Antonio Salonia, afirmaba también que el Proyecto constituía una respuesta «concreta y ambiciosa al vertiginoso proceso de cambio y a la necesidad perentoria de crear nuevas estructuras que sirvan eficientemente al desarrollo nacional», que requería una verdadera industrialización. ${ }^{36}$

Durante la gestión este ministro se inició una microexperiencia del ciclo intermedio en cuatro escuelas primarias nacionales y se crearon los grupos de trabajo para la elaboración de los planes de estudio del nivel medio. En este nivel, no obstante, se introdujo un nuevo formato institucional que se llamó escuelas medias polivalentes a través de las cuales se proporcionaba cultura general y especialidades diversas con

\footnotetext{
32 Cirigliano, 1971; citado en Laura Rodríguez, «Los católicos desarrollistas», 168.

${ }^{33}$ Secretaría de Estado de Cultura y Educación, «3. ${ }^{a}$ Reunión nacional».

${ }^{34}$ Ministerio de Educación y Cultura, «Transcripción del texto del discurso del Dr. Dardo Pérez Guilhou pronunciado el 11 de setiembre de 1969", Boletín informativo del servicio de enseñanza superior, normal, media y técnica, n. 7 (1970). Biblioteca Pedagógica Eudoro Díaz; «Pérez Guilhou: "se hace necesario replantear el sistema educacional”", Clarín, 6/4/1970.

35 «El año lectivo 1970 inicióse oficialmente», La Capital, 17/3/1970.

36 «La reforma educativa y el plan de aplicación», Clarín, 7/1/1970; "Aspectos de la reforma en la enseñanza expuso el subsecretario de educación», Clarín, 30/7/70.
} 
una mínima inversión ya que hacían uso de los talleres de las escuelas técnicas. ${ }^{37}$ Otra experiencia «colateral» a la Reforma fue el Proyecto 13, que cambiaba el régimen laboral de los profesores a través de la designación de cargos - en lugar de horas de clases- para que cumpliesen con mayor eficacia su labor. ${ }^{38}$

Mediante los «Acuerdos de Santa Fe», alcanzados en el marco de la IV Reunión de Ministros de Educación convocada en mayo de 1970, las autoridades avanzaron en la proyección de la Reforma y aseguraron que el Programa Educativo Nacional aspiraba a crear en el «hombre argentino» las condiciones económico-sociales y espirituales de su «realización integral», en coincidencia con un destino de grandeza para el país, acelerando el proceso de modernización y creando «una estructura social mejor organizada y más justa». ${ }^{39}$ El programa reformista adquirió una nueva denominación pero mantuvo las iniciativas de extender la escolaridad y de planificar la oferta educativa según la demanda de mano de obra. También continuaba presente la intención de descentralizar el sistema para responder a los requerimientos regionales, lo cual implicaba distribuir e involucrar a más actores en la administración escolar. ${ }^{40}$

Luego de una ola de manifestaciones populares agresivas en repudio por la política económica, la caída del salario real y la ausencia de canales para una transición democrática, la Junta Militar sustituyó en forma precipitada al presidente Onganía por el general Roberto Levingston, buscando pacificar el descontrol social con medidas nacionalistas y levemente distributivas. Debido al cambio de gobierno, el ministro Pérez Guilhou fue reemplazado por José Luis Cantini (3/7/1970-15/5/1971). El programa de la Reforma y los Acuerdos de Santa Fe continuaron vigentes y se elaboraron los instrumentos jurídicos para el cambio educativo. Los ministros de todo el país definieron los objetivos de cada uno de los niveles. Al intermedio le correspondía estimular y canalizar el desarrollo

\footnotetext{
37 Ministerio de Cultura y Educación, «Creación de un Grupo de Trabajo. Resolución N. . 493», Boletín de comunicaciones, XV, n. ${ }^{\circ} 12$ (1970). CeNDIE; Ministerio de Cultura y Educación, "Crease el Ciclo Básico Polivalente. Resolución N. ${ }^{\circ}$ 670», Boletín de comunicaciones, XV, n. 13 (1970). CeNDIE.

${ }^{38}$ CONET, «Informe. Resolución ministerial N. ${ }^{\circ} 1371 »$, Memorandom (1971). CeNDIE.

39 Ministerio de Educación y Cultura, «Representantes de la Provincia de Santa Fe ante la Comisión Nacional de Análisis y Evaluación del Sistema Educativo», Boletín de información educativa, año 8, n. ${ }^{\circ} 4$ (1971). Biblioteca pedagógica Eudoro Díaz.

40 «Tratan importantes proyectos los ministros de educación», La Capital, 13/5/1970.
} 
de aptitudes e intereses por medio de diversas experiencias que posibilitaran una decisión vocacional; promover la realización de experiencias de trabajo en función de los requerimientos del desarrollo económico regional; y promover la iniciación científica y tecnológica. Al nivel medio le asignaron la misión de lograr una intensificación y generalización de la capacitación profesional y técnica a partir de su extensión a otras modalidades de enseñanza. Las escuelas polivalentes debían garantizar trayectos formativos alternativos, capaces de responder a diversas demandas de calificación, sujetos a la elección, intereses y aptitudes del educando. La formación, además, debía preparar y motivar al alumno para su formación permanente. Aún no estaba definido el criterio de integración de la educación técnica a cargo del CONET en la Reforma, sin embargo el ciclo superior de la enseñanza técnica se homologaría al bachillerato por lo que se extendería por dos años, otorgaría un título de bachiller técnico y no sería obligatorio. ${ }^{41}$

La implementación de la Reforma implicaba descentralizar la conducción y la administración del sistema escolar. Los establecimientos educativos, los estamentos intermedios de conducción y los privados debían asumir nuevas responsabilidades, entre ellas elaborar el currículum, construir y mantener los edificios escolares. Quedaba reservado para los organismos superiores el planeamiento, la experimentación y la supervisión general. ${ }^{42}$ Dichos objetivos y disposiciones se instrumentaron en forma operativa en el Plan nacional de desarrollo y seguridad, sector educación (1971-1975) ${ }^{43}$ suscitando gran oposición social y docente. En forma simultánea a la aprobación por ley de dicho plan, el ministro de educación abrió instancias de consultas sobre el programa reformista, tras lo cual renunció. ${ }^{44}$

\footnotetext{
${ }^{41}$ Ministerio de Cultura y Educación, «Objetivos del Sistema Educativo. Proyecto de ley que ratifica los acuerdos de la IV Reunión de ministros de Santa Fe y fija los objetivos generales del sistema educativo argentino», (1970). CeNDIE; «¿Debe ser reformado el sistema educativo argentino? Opinan los maestros de enseñanza práctica sobre la reforma en el área de la educación técnica», Clarín, 7/1/1971.

42 «Río Negro, primera provincia que recibe la totalidad de los institutos de enseñanza», Clarín, 17/10/1970.

${ }_{43}$ Ministerio de Cultura y Educación, «Plan Nacional de Desarrollo y Seguridad 1971-1975», Boletín del Centro Nacional de Documentación e Información Educativa, n. 9 (1971). CeNDIE.

${ }_{44}$ «Río Negro, primera provincia que recibe la totalidad de los institutos de enseñanza», Clarín, 17/10/1970.
} 
Al asumir su sucesor, Gustavo Malek (29/5/1971-25/5/1973), 60.000 alumnos en la jurisdicción nacional — sobre un total de un millón- estaba experimentado la Reforma. La educación era presentada por el nuevo ministro como un factor necesario para el bienestar social, lo cual exigía que los cambios en los conocimientos, en las técnicas y en los procesos productivos fuesen asimilados por las instituciones escolares a través de la permanente y continua innovación. ${ }^{45}$ Según su óptica, el bajo crecimiento demográfico solo podría ser compensado con recursos humanos de alto nivel educativo, científico y tecnológico. De inmediato dio continuidad a la microexperiencia que venía desarrollándose en un limitado número de establecimientos desde la gestión de Pérez Guilhou, adecuándola a las posibilidades financieras, de infraestructura y de recursos humanos disponibles. No obstante, puso en dudas si podría contar con los fondos necesarios para sostener el plan educativo de 1972. Así, el ciclo intermedio, núcleo de la Reforma educacional, fue suspendido al iniciarse ese ciclo lectivo. Solo continúo funcionando el 9. ${ }^{\circ}$ grado de nivel intermedio en cuatro escuelas dependientes del Consejo nacional de educación y en una de la Superintendencia nacional de enseñanza privada, todas de la Capital Federal. ${ }^{46}$

Si bien se mantuvo el Proyecto $13^{47}$ y se continuaron abriendo escuelas polivalentes que incluían a la modalidad técnica, las innovaciones en el nivel medio se redujeron a modificaciones en el sistema de evaluación. En un marco de generalizadas críticas al programa de Reforma, el ministro presentó algunos reparos. Sostuvo que era necesario dar lugar al sector docente y a la comunidad educativa para definir la orientación de la modernización y renovación del sistema educativo. Además reconoció que existían problemas financieros, falta de apoyo, ausencia de capacitación docente y desactualización de los currículos. En consecuencia, y considerando

\footnotetext{
45 «A la situación del docente refirióse el ministro Malek», La Capital, 12/9/1971. Gustavo Malek, «La educación es responsabilidad de todos los argentinos» (1971). CeNDIE.

46 «Estadística educativa: 16 ministros en 20 años», Clarín, 23/07/1971; «Tenemos un plan educativo para 1972, pero falta saber si habrá fondos para aplicarlo», Clarín, 27/12/1971; Ministerio de Cultura y Educación, «Continuará hasta 1972 la microexperiencia iniciada en 1970. Resolución N. 2786», Boletín de comunicaciones, XV, n. 47 (1971). CeNDIE; Ministerio de Cultura y Educación, «Normas para el ingreso de exalumnos de escuelas en la que se llevó a cabo la microexperiencia. Resolución N. ${ }^{\circ} 26$ », Boletín de comunicaciones, XV, n. 57 (1972). CeNDIE; «Fue anulado el ciclo intermedio. Lo dijo Rocca en ausencia de Malek», La Capital, 11/3/1972.
}

${ }^{47}$ Ministerio de Cultura y Educación, «Nuevo régimen laboral de profesores por cargos docentes. Ley N. ${ }^{\circ}$ 19514», Boletín de comunicaciones, XV, n. 58 (1972). CeNDIE. 
que debía ser revisado el programa reformista, suspendió su aplicación y designó una comisión nacional de evaluación del sistema educativo. Esta aprobó las medidas del programa, pero evaluó como negativo el proceso de implantación de la misma. ${ }^{48}$

Con posterioridad, en la Reunión de Ministros se ratificaron las metas y objetivos para el campo educativo que estaban presentes en el Plan nacional de desarrollo y seguridad. Coincidían en que la formación de recursos humanos debía ser acorde con las necesidades regionales y con las demandas del mercado ocupacional, llegando a todos los sectores sociales. Para avanzar en la Reforma, propusieron la creación del Consejo federal de educación como órgano de consenso a nivel nacional. ${ }^{49}$

\section{EL CONET ENTRE LA REFORMA DEL ESTADO Y DE LA EDUCACIÓN}

En mayo de 1969, el general de brigada retirado Ovidio Jesús Antonio Solari (25/7/1966- 25/8/1969) — que fue designado presidente del CONET - presentó objeciones a la nueva estructura educativa. Entendía que era conveniente desdoblar el ciclo intermedio de modo que sus dos primeros grados, de carácter prevocacional, fuesen absorbidos por la escuela primaria y sus dos últimos años, de orientación vocacional, por la enseñanza media. La enseñanza técnica de nivel medio destinada a varones debía continuar proporcionando los certificados de «auxiliar técnico» y de "técnico», aunque extendiéndose para sumar a los contenidos habituales otros de Filosofía, Sociología y Economía. ${ }^{50}$ Sus recomendaciones no fueron consideradas; en agosto de 1969 fue reemplazado

\footnotetext{
48 Gustavo Malek, «La educación es»; Ministerio de Cultura y Educación, «Se suspenden las medidas de inmediata aplicación en la Reforma educativa. Resolución N. ${ }^{\circ}$ 1734», Boletín de comunicaciones, XV, n. 40 (1971). CeNDIE; Ministerio de Cultura y Educación, «Crease la Comisión nacional de análisis y evaluación del sistema educativo. Resolución N. ${ }^{\circ} 1821$ », Boletín de comunicaciones, XV, n. ${ }^{\circ} 40$ (1971). CeNDIE; Laura Rodríguez, «Los católicos desarrollistas».

49 Boletín Oficial, «Ley N. ${ }^{\circ}$ 20016/72», año LXXXI, n. 22.582 (1973); Ministerio de Cultura y Educación, «Reunión de ministros de educación. Se ratifica el Acuerdo. Decreto N. ${ }^{4521}$ », Boletín de comunicaciones, XV, n. ${ }^{\circ} 8$ (1971). CeNDIE.

50 «Conclusiones. Información producida por el CONET relativa a la nota de la Oficina sectorial de desarrollo educación. Solicitando se emita opinión sobre la publicación titulada "Reforma Educativa." Desarrollo del proyecto aprobado por Resolución N. ${ }^{\circ}$ 944/68 (primer esbozo). Anexo Informes del Consejo nacional de educación, Administración nacional enseñanza media y superior, Superintendencia nacional de educación privada con relación a la Resolución ministerial N. ${ }^{\circ}$ 19734/71 » (1969). CeNDIE.
} 
por César García (25/8/1969-28/6/1971) y al mes siguiente la Reforma se hizo pública.

El nuevo presidente del CONET tenía una posición diferente a la de su predecesor. Afirmaba que la Reforma era compatible y podía concretarse con la estructura de enseñanza que mantenía el organismo. Argumentaba que los dos primeros años del ciclo básico pasarían a constituir los dos últimos del ciclo intermedio, ya que ambos poseían un «alto» contenido vocacional. Sostenía que en el ciclo básico, el alumno, además de cursar materias de orientación técnica y humanística, realizaba trabajos prácticos rotativos en los talleres de las ENET. Respecto al ciclo superior, el funcionario postulaba que era una instancia de especialización por lo que había convocado a una comisión para que reformulara sus planes y programas. Aspiraba a lograr la formación de un «técnico polivalente» conforme a las variaciones del mercado ocupacional, por lo que los planes y programas debían sujetarse al ritmo dinámico de la tecnología, introducir nuevas áreas de conocimientos y excluir las obsoletas. ${ }^{51}$

Durante la gestión del ministro Pérez Guilhou, cuando comenzó a implementarse la Reforma en un número reducido de escuelas, el CONET y la Administración nacional de educación media y superior organizaron ciclos básicos polivalentes de doble turno sobre la base de ciclos básicos comunes con orientación bachillerato y comercial, en Aimogasta (La Rioja), y con orientación bachillerato, comercial y técnico, en Ushuaia (Tierra del Fuego). El Proyecto 13 afectó a 47 establecimientos secundarios, dos de los cuales dependían del CONET: la ENET N. ${ }^{\circ} 16$, de Capital Federal y la N. ${ }^{\circ} 1$ de San Justo (Buenos Aires). Como esta experiencia se estaba desarrollando también en dos escuelas privadas de fábrica bonaerenses y en el Instituto politécnico Berazategui fueron supervisadas en el marco de este proyecto. ${ }^{52}$

El ministro Pérez Guilhou fue sucedido por Cantini. Si bien cuando asumió respetó los Acuerdos de Santa Fe y proyectó la ampliación de la

\footnotetext{
51 «Perspectiva estudiantil de la enseñanza técnica», Clarín, 13/1/1970.

52 «El año lectivo 1970 inicióse oficialmente», La Capital, 17/3/1970; «Se aplicará un régimen experimental para profesores de enseñanza media. Serán designados por tiempo completo o parcial durante 1970", Clarín, 5/3/70; Ministerio de Cultura y Educación, Resolución N. ${ }^{\circ}$ 658, Boletín de comunicaciones, XV, n. 13 (1970). CeNDIE; Ministerio de Cultura y Educación, "Ciclo básico polivalente», Boletín del Centro nacional de documentación e información educativa, n. ${ }^{\circ}$ 1970. CeNDIE.
} 
microexperiencia, durante su gestión la Reforma educativa se mantuvo en proceso de estudio en el área de la educación técnica, concretándose solo la apertura de nuevas escuelas polivalentes. En 1971, en forma simultánea a la sanción del Plan nacional de desarrollo y seguridad, el ministro inició un programa de consultas acerca del mismo a diferentes funcionarios del sistema. El informe del supervisor general pedagógico del CONET, Jorge Antonio Brescia, manifestó una contundente oposición a los bachilleratos en el ámbito del organismo. Defendía la formación profesional de los técnicos y ponía reparos a la nueva estructura: consideraba incompatible iniciar la carrera de técnico (el ciclo superior de la estructura que estaba vigente en el CONET) tras el ciclo intermedio, presumiendo que los contenidos serían insuficientes..$^{53}$

En ese marco - aunque sin ser convocados desde el gobierno- distintos gremios del profesorado técnico expresaron su oposición a la Reforma. La Asociación de maestros de enseñanza práctica cuestionó la anulación del ciclo básico de la enseñanza técnica y su reemplazo por el intermedio, siendo que la enseñanza técnica destinada a varones se «desintegraría» al «destruir» la carrera de auxiliar y al cambiar la estructura curricular de la formación del técnico. Se pronunciaban también por la falta de especificidad respecto al alcance del ciclo intermedio: el ciclo de profesiones femeninas tenía correspondencia con el ciclo básico y el reemplazo del mismo por el intermedio, hacía incierto el futuro de la propuesta de enseñanza destinada a las mujeres. El Acuerdo de nucleamiento docente, por su parte, expresó que la Reforma conducía al cierre de los establecimientos dependientes del CONET. Los directivos de DUETO defendían la estructura tradicional de la enseñanza del CONET por tratarse de una modalidad con objetivos precisos. La especificidad debía reflejarse en un currículo propio, que atendiese a la formación general y a la adquisición de un grado de profesionalidad específica en las disciplinas industriales. Aseguraban que la Reforma no era compatible con la formación de técnicos, que demandaba doble escolaridad por el trabajo en talleres. ${ }^{54}$

\footnotetext{
${ }_{53}$ Ministerio de Cultura y Educación, Resolución N. ${ }^{\circ}$ 1271. Aplicación de la Reforma Educativa con carácter de micro experiencia, Boletín de comunicaciones, XV, n. ${ }^{\circ} 19$ (1970). CeNDIE; «Copia de informe producido en el expte. del misterio de cultura y educación $\mathrm{N}^{\circ}$ 2559/71 sobre escuelas de bachillerato en el ámbito del CONET» (1971). CeNDIE.

54 «Opinión de AMEP en la reforma de la enseñanza», Clarín, 22/01/70. «Apoyan la autonomía del CONET», Clarín, 28/8/70. "Docentes formulan objeciones a la nueva política educativa. Consideraciones elevadas por AMEP al Ministro Pérez Guilhou, a quien solicitan audiencia», La Capital,
} 
El ministro renunció luego de que fue aprobado el Plan nacional de desarrollo y seguridad. ${ }^{55}$ El ingeniero Luinor Vilches sucedió a García en la dirección del CONET (30/6/1971-25/5/1973). Sostenía que la educación debía difundir las innovaciones del sistema productivo para promocionar el progreso económico. Ante la progresiva introducción de cambios tecnológicos, las propuestas educacionales debían proporcionar una formación teórica de base científica sólida para favorecer a la adaptación dinámica de los egresados a los empleos y postergar la especialización a instancias de formación permanente. Afirmaba, además, que la especialización de los recursos humanos debía ser una responsabilidad compartida entre el Estado y el sector empresario. ${ }^{56}$

Al tiempo que se discutían los alcances de los cambios en las propuestas curriculares de nivel medio del CONET, el organismo fue afectado por el proceso de racionalización de las estructuras del Estado. Por ley de creación era un organismo autárquico con una estructura de gobierno colegiada. Pese al lugar que los funcionarios otorgaron en sus discursos a la participación de actores representativos de la sociedad en la planificación de la política educacional, la colegiatura del CONET fue sujeta a un derrotero particular, que tuvo encuentros y desencuentros con la política de descentralización. En 1968 le fue suprimido su carácter colegiado ${ }^{57} \mathrm{y}$, al año siguiente, su autarquía financiera. ${ }^{58} \mathrm{~A}$ esto se

19/5/1970; «Apoyan la autonomía del CONET», Clarín, 28/8/70; “¿Debe ser reformado el sistema educativo argentino? Opinan los Maestros de Enseñanza Práctica sobre la reforma en el área de la educación técnica», Clarín, 7/1/1971; «¿Debe ser reformado el sistema educativo argentino? Directivos de DUETO opinan sobre la reforma en la enseñanza técnica», Clarín, 13/1/1971.

55 Laura Rodríguez, «Los católicos desarrollistas»; Catalán, pese a los consensos alcanzados por los ministros acerca de la propuesta de Reforma, sostenía que era necesario efectuar una nueva revisión del programa reformista por lo que impulsó una comisión integrada por entidades representativas de distintos sectores sociales, entre las que destacamos la Unión Industrial Argentina, Confederación General Económica, Aciel y Sociedad Rural Argentina para efectuar dicho análisis ( «Fue creado un órgano consultor educativo. Con su participación se adecuarán sistemas en el área cultural», $\mathrm{La}$ Capital, 9/5/1971). No obstante, al ratificarse la Reforma a través de la sanción de la ley que avaló el Plan Nacional Desarrollo y Seguridad, Cantini renunció («Cantini presentó ayer su renuncia al general Lanusse», La Capital, 15/5/1971).

${ }^{56}$ Luinor Vilches, «La educación técnica y el desarrollo económico social» (1972). CeNDIE

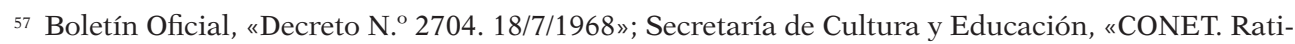
ficase la designación del presidente. Decreto N. ${ }^{\circ} 3691 »$ (1968). CeNDIE.

${ }_{58}$ No obstante, por unos meses, durante 1970, se le restituyó el carácter descentralizado y la autonomía operativa porque así debía funcionar según el presupuesto de 1970 (Boletín Oficial, «Educación. Se autoriza al CONET a operar como organismo descentralizado. Decreto N $^{\circ} 1777$ » 1970). 
sumó la sanción de la Ley N. ${ }^{\circ} 18586$ que dispuso la transferencia de todas las escuelas nacionales a las provincias, fundándose en la conveniencia de centralizar la conducción y descentralizar la ejecución de la educación. Su alcance fue limitado debido a que solo las ENET localizadas en la provincia de Río Negro pasaron a la jurisdicción provincial, mediante la transferencia de las obligaciones escolares que no contempló el traspaso del impuesto para la educación técnica ${ }^{59}$ al fisco provincial, ni las equivalencias de estudios y carreras docentes. ${ }^{60}$ Las dificultades de orden técnico, administrativo y económico que generó en la provincia le impidieron sostener dichos establecimientos, de modo que en septiembre de 1972, las cuatro escuelas transferidas volvieron a la jurisdicción nacional. ${ }^{61}$

En septiembre de 1971 se sancionó la Ley N. ${ }^{\circ} 19206$ que modificó la ley de creación del CONET: restituyó su colegiatura al tiempo que suprimió su autarquía originaria para organizar y gobernar la educación técnica. Si bien los gremios docentes, las entidades empresarias, el Ministerio de Trabajo y la central obrera reconocida nombraron a sus respectivos delegados en los plazos estipulados, el cuerpo colegiado se constituyó en marzo de $1972^{62}$ El renovado organismo debía:

Promover la capacitación, actualización, especialización y formación profesional y artesanal de los recursos requeridos por las prioridades y modalidades del proceso de desarrollo, modernización y cambio social y económico de la nación a través de la programación, normativización, coordinación, investigación y supervisión general de la educación técnica. La administración y

\footnotetext{
${ }^{59}$ El presupuesto del CONET se componía de los aportes del Estado, de donaciones efectuadas por particulares y de los ingresos provenientes del impuesto a la educación técnica. Este último era una obligación tributaria de las empresas industriales que representaba un ingreso al CONET del 0,1\% de lo que cada firma pagaba en salarios. Los industriales podían optar por hacer el aporte en forma directa al organismo o bien subvencionar escuelas técnicas o cursos profesionales privados aprobados por el CONET.

${ }^{60}$ Ministerio de Cultura y Educación, «Transfiéranse a las Provincias Organismos Nacionales que existen en su territorio. Ley N. ${ }^{\circ} 18586 »$, Boletín de Comunicaciones, n. ${ }^{\circ}$. CeNDIE; «Río Negro, primera provincia que recibe la totalidad de los institutos de enseñanza», Clarín, 17/10/1970.

${ }^{61}$ CONET, «Decreto N. ${ }^{\circ}$ 6.581. 26/9/1972», Boletín del CONET, n. ${ }^{\circ} 358,23 / 10 / 1972$.

62 "Anunció Malek la política educativa», Clarín, 23/12/71; «Recobra su autonomía la enseñanza técnica. Asumieron sus cargos los nuevos vocales del CONET», Clarín, 7/3/1972.
} 
dirección de las unidades escuelas, estará a cargo de los directores de las mismas. ${ }^{63}$

De modo que debía «lograr una efectiva delegación de autoridad en la faz operativa tanto en los aspectos académicos como en los económicos financieros, hacia las autoridades de cada unidad escolar».64 Esta legislación constituyó un antecedente de la Ley N. ${ }^{\circ}$ 20016, sancionada a fines de 1972, que estableció la descentralización administrativa de las escuelas: el CONET se convirtió en un organismo descentralizado en lo referido a la administración y conducción operativa de las unidades escolares, reservándole responsabilidad sobre «los aspectos generales de planeamiento, normatización y formulación de políticas». ${ }^{65}$ En forma transicional, la ley pautaba tres tipos de establecimientos, con distintas atribuciones. Las unidades educativas centralizadas continuarían con su funcionamiento habitual debido a que el CONET las seguía administrando integralmente. Las escuelas que adquirían nuevas responsabilidades serían desconcentradas, en las que ese organismo se limitaba a ejercer supervisión pedagógica, presupuestaria, administrativa contable y operativa; y las descentralizadas, en las que ejercía solamente supervisión pedagógica y operativa y compatibilización presupuestaria. ${ }^{66} \mathrm{De}$ este modo, se independizaban de su responsabilidad financiera un conjunto de establecimientos educativos, cuyo financiamiento y administración quedaba en manos de sus directivos y de la comunidad.

Las escuelas privadas que eran mantenidas por el impuesto para la educación técnica, a partir de la sanción de la Ley N. ${ }^{\circ}$ 20016, pasaban a ser establecimientos descentralizados. Esto suscitó la crítica de sectores comunistas, que sostenían que la legislación habilitaba a las grandes empresas a penetrar y absorber a los colegios que aún no estaban bajo su directo control. Si los contenidos, metodologías y actividades de enseñanza quedaban a criterio de las comunidades educativas estos podían ser directamente vinculados a los intereses de las industrias que las sostenían, ultra especializados y fragmentados, contrapuestos a la

\footnotetext{
${ }_{63}$ Anales de la Legislación Argentina, «Ley N. ${ }^{\circ}$ 19206/71. Art. 4; inc. 5» Tomo ADL XXXI-C: 2833.

${ }^{64}$ Anales de la Legislación Argentina, «Ley N. ${ }^{\circ}$ 19206/71. Art. 4; inc. 5» Tomo ADL XXXI-C: 2833.

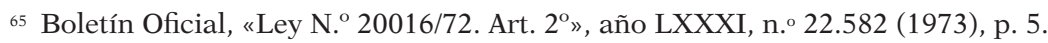

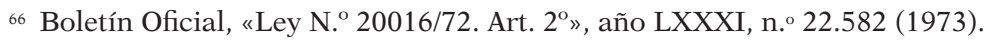


premisa «educación integral» que había sido sostenida por la derogada ley de creación del CONET. ${ }^{67}$ De acuerdo con el periódico comunista Política Obrera el cuerpo docente, los alumnos secundarios y técnicos lograron la postergación de su implementación hasta septiembre de 1973, cuando fue derogada. ${ }^{6}$

\section{LA ENSEÑANZA TÉCNICA: OFERTA EDUCATIVA Y LIMITACIONES PRESUPUESTARIAS}

El derrotero de la oferta del CONET durante la Revolución argentina no estuvo exento de contradicciones y oposiciones a los principios y proyecciones sostenidos por las autoridades nacionales. Hacia 1967, al tiempo que se proyectaban reformulaciones en todo el sistema educativo, los funcionarios del CONET intentaban, con escasos resultados, diversificar su oferta teniendo en cuenta la regionalización del país elaborada por la CONADE para satisfacer con eficacia las demandas de mano de obra. En este marco se regionalizaron las Inspecciones técnicas de escuelas, ${ }^{69}$ con el propósito de redistribuir la oferta atendiendo a las necesidades más urgentes de las distintas regiones económicas, ${ }^{70}$ aunque con escaso impacto en los cambios curriculares.

Desde 1968 las acciones del CONET se vincularon más a la ratificación de los planes de estudios diseñados a mediados de la década que a su actualización. ${ }^{71}$ Continuaron vigentes los planes de estudio de los ciclos de manualidades femeninas, de profesiones femeninas, de práctica comercial y de dibujo publicitario; los de los cursos prácticos y técnicos

\footnotetext{
${ }^{67}$ «Leyes 20.014, 15 y 16. Descalificación, privatización e ingeniería del gran capital y de la iglesia en la escuela», Politica Obrera, n. ${ }^{\circ} 150,23 / 4 / 73$.

68 "Los técnicos se organizan para liquidar el Decreto Jorge de la Torre», Política Obrera, n. ${ }^{\circ}$ 152, 4/5/73; «Importante la definición de la coordinadora. Ratificando las denuncias de nuestro partido y la TERS», Política Obrera, n. ${ }^{\circ}$ 152, 4/5/73; Boletín Oficial, «Decreto N. ${ }^{\circ} 20.350$ ", año LXXXI, n. 22664 (1973); «Manifiesto de la Unión de Juventudes Socialistas» Política Obrera, n. ${ }^{\circ}$ 153, 11/5/73; «Regirán a partir de septiembre. Derogar las Leyes 20.014,15 y 16», Política Obrera, n. ${ }^{154}$. 18/5/73; «Decreto N. ${ }^{\circ} 1182 / 72$. 13/3/73».

${ }^{69}$ CONET, Resolución N. ${ }^{\circ}$ 340. 28/3/81968, Boletín del CONET, n. ${ }^{\circ}$ 159, 8/4/1968.

70 José Mariano Astigueta, 1968. Año del cambio en Educación, Secretaría de Estado de Cultura y Educación (1968).

${ }^{71} \mathrm{MCE}$, «Aprobar los planes de Estudios para el Ciclo Básico Nocturno y Cursos Nocturnos para Formación de Operarios del CONET, Resolución N. ${ }^{\circ}$ 345. 29/4/68», Boletín de Comunicaciones, XIV, n. 35 (1968). «Perspectiva estudiantil de la enseñanza técnica», Clarín, 13/1/1970.
} 
terminales, que sostenían articulación vertical con los recientemente mencionados; los del ciclo básico común y de doble escolaridad; y los de auxiliar técnico, que databan de 1965. Las innovaciones se centraron en la creación de nuevos cursos técnicos terminales, destinados a egresados del ciclo básico o de los ciclos de profesiones femeninas, práctica comercial y dibujo publicitario, que se extendían por dos años y otorgaban los títulos de decorador de interiores, técnico en fotografía, auxiliar técnico para laboratorio químico y técnico en artes decorativas; ${ }^{72}$ a la creación de las carreras de tres años de técnico en administración empresaria y de técnico en administración pública, ${ }^{73}$ y a la actualización de los currículos de algunas especialidades del ciclo superior. ${ }^{74}$

Los convenios con organismos públicos y privados, instituciones de la sociedad civil y empresas permitieron otorgarle cierta impronta regional a la oferta de nivel medio del CONET. Las contrapartes al CONET estaban interesadas en satisfacer demandas específicas de mano de obra, por lo que se amplió la oferta considerando dichas necesidades. El alcance de estas acciones, sin embargo, fue limitado. Respondieron a demandas precisas sin alcanzar a reformular las propuestas de enseñanza. A comienzos de 1972, directivos e inspectores continuaban reclamando que la enseñanza técnica tuviese innovaciones que la adecuaran a los requerimientos de las economías regionales. ${ }^{75}$ A fines de ese año, mediante la Ley N. ${ }^{\circ} 20016$, se intentó - una vez más- regionalizar la enseñanza a través de la reorganización del gobierno de la educación técnica. Los objetivos, contenidos, metodologías y actividades debían ser pautados en cada escuela, considerando las características del alumnado y del entorno regional. La nueva

\footnotetext{
72 CONET, Planes de estudio educación técnica (1969).
}

${ }^{73}$ Ministerio de Cultura y Educación, Resolución N. ${ }^{\circ}$ 345. Aprobar los planes de estudios para el ciclo básico nocturno y cursos nocturnos para formación de operarios del CONET, Boletín de comunicaciones, XIV, n. 35 (1968). CeNDIE; Resolución N. ${ }^{\circ}$ 346. Curso técnico de administración de empresas, Boletín de comunicaciones, XIV, n. 35 (1968). CeNDIE; Resolución N. ${ }^{\circ} 402$. Apruébese planes de estudios, Boletín de comunicaciones, XIV, n. 36 (1968). CeNDIE; «Perspectiva estudiantil de la enseñanza técnica», Clarín, 13/1/1970.

${ }^{74}$ CONET, Resolución N. ${ }^{\circ}$ 189. 2/3/1967, Boletín del CONET, n. ${ }^{\circ} 113.17 / 4 / 1967$; Resolución N. ${ }^{\circ} 401$. 13/4/1970, Boletín del CONET, n. ${ }^{\circ}$ 250. 18/5/1970; Resolución N. ${ }^{\circ} 4726.14 / 3 / 1972$, Boletín del CONET, n. ${ }^{\circ} 335.8 / 5 / 1972$, 373; Resolución N. ${ }^{\circ} 2899$. 11/6/1971, Boletín del CONET, n. ${ }^{\circ}$ 299. 28/6/1971. Resolución N. .o 4078. 13/12/1971, Boletín del CONET, n. ${ }^{\circ} 326.6 / 3 / 1972$; Resolución N. ${ }^{\circ}$ 280. 23/5/1972, Boletín del CONET, n. ${ }^{\circ} 339.5 / 6 / 1972$; «Educación técnica ¿Qué piensa hacer el CONET en el presente año lectivo?», Clarín, 15/3/1972.

${ }^{75}$ Boletín Oficial, «Ley N. ${ }^{\circ}$ 16964, 30/9/1966»; CONET «Algunas consideraciones sobre». 
dinámica, según se argumentaba, estimularía la creatividad docente y su jerarquización profesional, así como «la participación de la comunidad en el gobierno educativo [...] en la administración y en la complementación de los currículos». ${ }^{76}$ Sin embargo la legislación no entró en vigencia.

Las autoridades del CONET sostenían que la educación del adulto era una inversión más rentable que la de los menores. ${ }^{77} \mathrm{~A}$ lo largo del período la oferta de cursos profesionales nocturnos destinados a operarios se amplió con la apertura de 37 nuevos cursos. Inicialmente se ratificaron los planes de ajuste mecánico, asistente químico, bobinado eléctrico, fresado mecánico, instalador electricista, mecánica del automotor, radioarmado y televisión; tornería mecánica. Luego, se incorporaron las especialidades en aparatos ortopédicos, artes gráficas, conducción de motores navales, industria del calzado, instalaciones de gas domiciliario, mantenimiento de aviones, óptica, ortesis y prótesis, radio-operadores, refrigeración y aire acondicionado, industria del vestido y carpinteros de muebles. En 1971, aprobaron estos cursos 1.335 alumnos. ${ }^{78}$

Respecto al ciclo de profesiones femeninas, hasta el comienzo de la gestión de Vilches, no se amplió la oferta. Desde entonces se efectuaron cambios tendientes a eliminar de la educación media del CONET los circuitos diferenciados. A partir de 1972 se comenzaron a reemplazar los Ciclos de Profesiones y Manualidades Femeninas por el Ciclo Básico de doble escolaridad que permitía continuar los estudios en el ciclo superior y desde 1973 admitía a varones. En 1972 se reemplazaron 29 ciclos de profesiones femeninas por el ciclo básico de doble escolaridad y, al año siguiente, $30 .{ }^{79}$

Existieron problemas que atravesaron todo el período. Diferentes políticas intentaron hacer frente a los recortes presupuestarios y al crecimiento de la matrícula en el nivel medio. En este sentido, la idea de racionalización estatal pregonada por los funcionarios de la Revolución

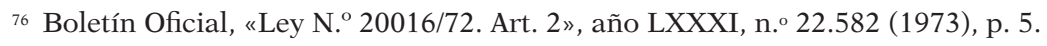

77 CONET «Algunas consideraciones sobre».

${ }^{78}$ Luinor Vilches, «La educación técnica y el desarrollo económico social», Conferencia pronunciada por el Pte. del CONET en el Círculo Miliar. CONET. 30/10/1972.

${ }^{79}$ CONET, Resolución N. ${ }^{\circ}$ 176. 2/5/1972, Boletín del CONET n. ${ }^{\circ} 336$. 15/5/1973; Resolución N. 377. 29/3/1973, Boletín del CONET n. ${ }^{\circ} 376.16 / 4 / 1973$.
} 
argentina se oponía a la centralidad que adquirió la educación técnica en sus discursos y que tuvo correlato en las inscripciones de alumnos. El aumento de la cantidad de estudiantes fue progresivo a lo largo de la década de los sesenta. En 1966 la matrícula de la educación media y profesional dependiente del CONET era de 131.259 y cuatro años más tarde, en 1970, de 148.400 estudiantes. Durante ese lapso, en que el crecimiento anual de la matrícula promedio fue de 4.285 alumnos, se abrieron 13 ciclos superiores, dos ciclos básicos, 20 cursos de término y dos ENET. ${ }^{80}$ $\mathrm{Al}$ mismo tiempo, se fusionaron 29 ENET en 13 escuelas, ${ }^{81}$ y se ordenó a las direcciones que no debían cubrirse cargos de maestras y de maestras ayudantes de enseñanza práctica cuando la inscripción fuese menor a diez alumnas en los ciclos de profesiones y manualidades femeninas y en los cursos prácticos destinados exclusivamente a mujeres. ${ }^{82}$

La tendencia al aumento de la matrícula se acentuó cuando, en 1970, se quitó el examen de ingreso en las ENET cuyas vacantes no excedían al número de inscriptos. La matrícula experimentó un crecimiento exabrupto, siendo 160.045 los estudiantes del CONET en 1971 y 169.737 al año siguiente. ${ }^{83}$ Ante tal aumento de la demanda de educación técnica

80 CONET, Resolución N.॰ 267. 16/3/1967, Boletín del CONET n. ${ }^{\circ}$ 117. 2/5/1967; Resolución N. 396. 6/4/1967, Boletín del CONET n. ${ }^{\circ}$ 119. 13/5/1967; Resolución N. ${ }^{\circ}$ 176. 2/3/1967, Boletín del CONET $n .^{\circ}$ 166. 27/5/1968; Resolución N. ${ }^{\circ} 238$. 7/3/1968, Boletín del CONET n. ${ }^{\circ}$ 160. 15/4/1968; Resolución N. ${ }^{\circ}$ 1855. 15/12/1966, Boletín del CONET n. ${ }^{\circ}$ 118. 8/5/1967; Resolución N. ${ }^{\circ}$ 393. 6/4/1967, Boletín del CONET n. 119. 13/5/1967; Resolución N.o 4323. 10/4/1968, Boletín del CONET n. 168. 10/6/1968; Resolución N. ${ }^{\circ}$ 406. 6/4/1967, Boletín del CONET n. ${ }^{\circ}$ 167. 3/6/1968; Resolución N. ${ }^{\circ} 792$ 10/6/1968, Boletín del CONET n. ${ }^{\circ}$ 171. 1/7/1968; Resolución N. ${ }^{\circ}$ 380. 28/3/1969, Boletín del CONET n. ${ }^{\circ} 209$. 2/6/1969; Resolución N.o 380. 28/3/1969, Boletín del CONET n. 209. 2/6/1969; Resolución N. ${ }^{\circ} 803$. 17/6/70, Boletín del CONET n. ${ }^{\circ}$ 258. 20/6/70; Resolución N. ${ }^{\circ}$ 206. 10/3/70, Boletín del CONET n. ${ }^{\circ} 259$. 27/7/70; «En la escuela técnica N.॰ 1 se creó un ciclo», La Capital, 10/5/1970, 5.

${ }^{81}$ CONET, Resolución N. ${ }^{\circ}$ 135. 22/2/1968, Boletín del CONET n. ${ }^{\circ}$ 164. 15/5/1968; Resolución N. ${ }^{\circ} 138$. 22/2/1968, Boletín del CONET n. ${ }^{\circ}$ 164. 15/5/1968; Resolución N. ${ }^{\circ}$ 188. 29/2/1968, Boletín del CONET $n .^{\circ}$ 164. 15/5/1968; Resolución N. ${ }^{\circ}$ 2044. 30/11/1967, Boletín del CONET n. ${ }^{\circ}$ 169. 17/6/1968; Resolución N. 2022. 5/12/1968, Boletín del CONET n. ${ }^{\circ}$ 194. 16/12/1968; Resolución N. 2023. 5/12/1968, Boletín del CONET n. ${ }^{\circ}$ 194. 16/12/1968; Resolución N. ${ }^{\circ}$ 2026. 5/12/1968, Boletín del CONET n. ${ }^{\circ} 194$. 16/12/1968; Resolución N. 2028. 5/12/1968, Boletín del CONET n. 194. 16/12/1968; Resolución N. ${ }^{\circ}$ 2020. 5/12/1968, Boletín del CONET n. ${ }^{\circ}$ 194. 16/12/1968; Resolución N. ${ }^{\circ} 2021.5 / 12 / 1968$, Boletín del CONET n..$^{\circ}$ 194. 16/12/1968; Resolución N..$^{\circ}$ 2027. 5/12/1968. Boletín del CONET n. ${ }^{\circ}$ 194. 16/12/1968; Resolución N.o 2024. 5/12/1968. Boletín del CONET n. ${ }^{\circ}$ 194. 16/12/1968; Resolución N.o 431. 30/11/1967. Boletín del CONET n. ${ }^{\circ}$ 169. 17/6/1968.

82 CONET, «Comunicado», 26/5/1968. Boletín del CONET n. ${ }^{\circ}$ 158. 1/4/1968, 163.

${ }_{83}$ Luinor Vilches, «La educación técnica y el desarrollo económico social, Conferencia pronunciada por el Pte. del CONET en el Círculo Miliar. CONET. 30/10/1972», Informaciones CENDIE N. ${ }^{\circ} 3$, 10/1969. CONET, Resolución N. ${ }^{\circ}$ 1614, 6/10/1969, Boletín del CONET, n. ${ }^{\circ}$ 273. 2/11/1970; Resolución N. ${ }^{\circ}$ 1616. 22/10/70, Boletín del CONET, $n$. $^{\circ} 312$. 4/10/1979; Resolución N. ${ }^{\circ}$ 3468. 16/9/1971, Boletín del 
y la falta de asientos en muchas ENET, el Ministerio de Cultura y Educación reubicó a los alumnos que habían rendido examen de ingreso para primer año y obtenido 40 o menos puntos en distintos establecimientos con disponibilidad de asientos y encomendó a una comisión un estudio integral de la situación y la confección de un plan de redistribución de las escuelas. Siguiendo dichos lineamientos se reacomodaron los cargos y las divisiones, según las demandas institucionales. ${ }^{84}$

En 1971 se abrieron 22 ciclos superiores y cuatro cursos de término. ${ }^{85}$ No obstante, el problema del número de aspirantes superior al de bancos en las ENET se reeditó. Para hacer frente al crecimiento vegetativo del estudiantado se dispuso que quienes, en 1970, habían aprobado la asignatura taller pero que habían repetido el tercer año del ciclo básico, podían optar por inscribirse en el curso de término y obtener, tras su promoción, un certificado de competencia profesional en el oficio cursado. En ese momento podrían completar el tercer año del ciclo básico adeudado rindiendo libres las asignaturas no aprobadas de ese año. Una vez aprobadas podrían permutar el certificado de competencia profesional por el de auxiliar técnico en el oficio cursado. ${ }^{86}$ Por entonces, la Unión Docentes de Educación Técnica denunciaba recortes presupuestarios y el pago atrasado de salarios. Exponía además la paradoja de que, al tiempo que el presupuesto del organismo había disminuido en 2.000 horas cátedras con respecto a 1970, se habían autorizado excepciones al pago del impuesto para la educación técnica por un monto que podría haber solucionado la insuficiencia presupuestaria. ${ }^{87}$

CONET. 30/10/1972; Resolución N. ${ }^{\circ}$ 1258. 17/10/1972, Boletín del CONET. CINTERFOR-OIT, 19641973. Formación profesional en América Latina, Montevideo (1974).

84 «Educación: enunció Pérez Guilhou planes previstos para este año», Clarín, 17/3/1970; «Ingreso y planes en las escuelas técnicas» Clarín, 16/2/1970; «El boom en la educación técnica: la electrónica», Clarín, 26/01/70; Ministerio de Cultura y Educación, « Resolución N. 412. Constituyese un Grupo de Trabajo», Boletín de comunicaciones, XV, n. ${ }^{\circ} 10$ (1970). CeNDIE.

${ }_{85}$ CONET, Resolución N. ${ }^{\circ}$ 1985. 30/12/1970, Boletín del CONET n. ${ }^{\circ}$ 282. 1/5/1971; Resolución N. ${ }^{\circ} 1866$. 2/12/1970, Boletín del CONET n. ${ }^{\circ}$ 281. 15/2/1971; Resolución N. ${ }^{\circ}$ 1974. 21/12/1970, Boletín del CONET $n .^{\circ}$ 281. 15/2/1971; Resolución N. ${ }^{\circ}$ 2361. 12/3/1971, Boletín del CONET n. ${ }^{\circ}$ 289. 19/4/1971; Resolución N. ${ }^{\circ}$ 2809. 31/5/1971, Boletín del CONET n. $298.21 / 6 / 1971$; «La esc. nacional de educación tec. "Manuel Pizarro" incorporó el ciclo superior», El Litoral, 18/3/1968, 4.

${ }_{86}$ CONET, Resolución N. ${ }^{\circ}$ 2364. 19/2/1971, Boletín del CONET n. ${ }^{\circ}$ 287. 5/4/1971; Circular N. 238. 12/4/71, Boletín del CONET $n .{ }^{\circ}$ 294. 24/5/1971.

87 "Docentes de educación técnica señalan los problemas de ese sector de la enseñanza», Clarín, $26 / 3 / 71$. 
Para el ciclo lectivo de 1972 el ministro Malek solicitó un aumento presupuestario del $46 \%$ y el presidente el CONET denunció públicamente que los recursos financieros eran retaceados. Si bien comenzaron a funcionar cuatro nuevas ENET; 24 nuevos ciclos superiores y tres ciclos básicos, ${ }^{88}$ se cerraron 13 establecimientos educativos. ${ }^{89}$ Pese a dicha ampliación, la cantidad de aspirantes continuó excediendo las posibilidades de los establecimientos. Numerosos alumnos que no habían sido promovidos de curso, se encontraron imposibilitados para reinscribirse en el año que debían repetir porque la cantidad de promovidos llenaba totalmente las vacantes disponibles. Frente a esta circunstancia el CONET dispuso que los alumnos repetidores que tenían aprobadas las asignaturas de carácter práctico — taller y dibujo lineal— podían rendir las materias teóricas que no habían aprobado en forma libre. Los que adeudaban los espacios curriculares prácticos no tenían opción para continuar sus estudios. ${ }^{90}$ Los alumnos que no podían ingresar al primer año de las escuelas técnicas por falta de vacantes, podían iniciar el ciclo básico en un colegio nacional o comercial, incorporarse en el cuatro año de término de las escuelas técnicas y luego continuar los estudios en el

\footnotetext{
88 «Malek llegó: hoy recibe al periodismo», Clarín, 15/12/1971; «Anunció Malek la política educativa», Clarín, 23/12/71; "El viernes último se realizó un acto de colación en la ENET N. ${ }^{\circ}$ 2», Clarín, 20/12/1971; «Informaron sobre la iniciación de nuevas etapas y desarrollo sobre convenio CONET-BID. Otra etapa», Clarín, 14/1/1972; «Importantes innovaciones en la enseñanza privada», La Capital, 22/3/1972. CONET, Resolución N. ${ }^{\circ}$ 4861. 27/3/72, Boletín del CONET n. 352. 11/9/1972; Resolución N. ${ }^{\circ}$ 4862. 27/3/72, Boletín del CONET n. ${ }^{\circ} 352$. 11/9/1972; Resolución N. ${ }^{\circ}$ 4863. 27/3/72, Boletín del CONET n. ${ }^{\circ}$ 352. 11/9/1972; Resolución N. ${ }^{\circ}$ 4864. 27/3/72, Boletín del CONET n.॰ 352. 11/9/1972; Resolución N. ${ }^{\circ} 4866$. 27/3/72, Boletín del CONET n. ${ }^{\circ} 352.11 / 9 / 1972$; Resolución N. ${ }^{\circ}$ 4867. 27/3/72, Boletín del CONET n. ${ }^{\circ}$ 352. 11/9/1972; Resolución N. ${ }^{\circ}$ 4868. 27/3/72, Boletín del CONET n. ${ }^{\circ}$ 352. 11/9/1972; Resolución N. ${ }^{\circ}$ 4860. 27/3/72, Boletín del CONET n. ${ }^{\circ} 352$. 1/9/1972; Resolución N. ${ }^{\circ}$ 4869. 27/3/72, Boletín del CONET n. ${ }^{\circ}$ 352. 11/9/1972; Resolución N. ${ }^{\circ} 4861$. 27/3/72, Boletín del CONET n. ${ }^{\circ}$ 352. 11/9/1972; Resolución N. ${ }^{\circ}$ 4870. 27/3/72, Boletín del CONET $n .^{\circ}$ 352. 11/9/1972; Resolución N. ${ }^{\circ}$ 4871. 27/3/72, Boletín del CONET n. ${ }^{\circ}$ 352. 11/9/1972; Resolución N. ${ }^{\circ}$ 4872. 27/3/72, Boletín del CONET n. ${ }^{\circ}$ 352. 1/9/1972; Resolución N. ${ }^{\circ} 4875$. 27/3/72, Boletín del CONET n. ${ }^{\circ} 352.11 / 9 / 1972$.
}

${ }^{89}$ CONET, Resolución N. ${ }^{\circ}$ 4861. 27/3/72, Boletín del CONET n. ${ }^{\circ}$ 352. 11/9/1972; Resolución N. ${ }^{\circ} 4862$. 27/3/72, Boletín del CONET n. ${ }^{\circ}$ 352. 11/9/1972; Resolución N. ${ }^{\circ}$ 4863. 27/3/72, Boletín del CONET $n .^{\circ}$ 352. 11/9/1972; Resolución N. ${ }^{\circ}$ 4864. 27/3/72, Boletín del CONET n. ${ }^{\circ}$ 352. 11/9/1972; Resolución N. ${ }^{\circ}$ 4866. 27/3/72, Boletín del CONET n. ${ }^{\circ}$ 352. 11/9/1972; Resolución N. ${ }^{\circ}$ 4867. 27/3/72, Boletín del CONET n. ${ }^{\circ}$ 352. 11/9/1972; Resolución N. ${ }^{\circ} 4868$. 27/3/72, Boletín del CONET n. ${ }^{\circ} 352.11 / 9 / 1972$; Resolución N. ${ }^{\circ}$ 4860. 27/3/72, Boletín del CONET n. ${ }^{\circ}$ 352. 1/9/1972; Resolución N. ${ }^{\circ}$ 4869. 27/3/72, Boletín del CONET n.$^{\circ}$ 352. 11/9/1972; Resolución N. ${ }^{\circ}$ 4870. 27/3/72, Boletín del CONET n. ${ }^{\circ} 352$. 11/9/1972; Resolución N. ${ }^{\circ}$ 4871. 27/3/72, Boletín del CONET n. ${ }^{\circ}$ 352. 11/9/1972; Resolución N. ${ }^{\circ}$ 4872. 27/3/72, Boletín del CONET n. ${ }^{\circ}$ 352. 1/9/1972; Resolución N. ${ }^{\circ} 4875$. 27/3/72, Boletín del CONET n. ${ }^{\circ} 352$. 11/9/1972.

90 «Parece que será una realidad el replanteo del sistema educativo», Clarín, 20/12/71; "Vacantes técnicas. Nota editorial», Clarín, 2/4/1972. 
ciclo superior técnico. De esta manera, en la práctica, la carrera de técnico se extendía a siete años, en lugar de seis.

Hacia 1972 existía el 71\% más de ciclos básicos de bachilleratos que en 1966; la cantidad de escuelas comerciales había crecido el 1\% y las ENET habían disminuido el 0,7\%, que representaba a 13 establecimientos.

\section{CONCLUSIONES}

A lo largo de la Revolución argentina los discursos e ideas desarrollistas atravesaron la conducción y la política educativa, manifestándose en el Proyecto de Reforma del sistema educativo nacional de 1968, en el Programa educativo nacional de 1970 y en el Plan nacional de desarrollo y seguridad (1971-1975).

Los problemas de la formación de recursos humanos y de la racionalización del gobierno de la educación fueron preocupaciones presentes en los pronunciamientos de todos los funcionarios del período. Existió una posición optimista respecto a las potencialidades la educación como base necesaria para la modernización tecnológica, económica y social. La enseñanza técnica apareció en un lugar central en el proceso de cambio y en el proyecto de país, al ser necesaria la capacitación de recursos humanos para un mercado de trabajo que se modernizaría.

El general Onganía, sus ministros y colaboradores consideraron a la educación técnica desde una perspectiva espiritualista y de educación integral, pero esta perdió presencia cuando en 1971 se sancionó Ley N. ${ }^{\circ} 19206$, que tornó al vínculo educación-trabajo más pragmático.

La planificación educativa fue vista como el instrumento para redefinir la estructura y la organización de los niveles y ciclos de la enseñanza, junto a la modificación del gobierno de la educación. En los discursos de las autoridades aparecían las dos variables como necesarias e interdependientes. No obstante, analizadas las transformaciones en el gobierno de la educación técnica, así como el alcance de la Reforma en la modalidad y las acciones para enfrentar el crecimiento de la matrícula, es evidente que el mayor cambio operó en la estructura de conducción del CONET. Las acciones orgánicas y funcionales emprendidas por todos los ministros estuvieron orientadas a descentralizar las responsabilidades pedagógicas 
y financieras, y a centralizar la planificación, experimentación y supervisión. La ley de transferencia de 1969 pudo haber sido un duro golpe para el CONET, pero su incidencia solo ocurrió en la provincia de Río Negro. Más perjudicial para este organismo fue la pérdida de su autarquía, con las Leyes N. 19206 y 20016, que además dejaban a un conjunto amplio de escuelas financiadas con el impuesto a la educación técnica supeditadas a los intereses de las empresas que las mantenían, y la enseñanza podía perder el carácter integral defendido por las autoridades del CONET. Resistida por estudiantes y docentes, la disposición no entró en vigencia y la estructura del organismo no cambió.

Por una parte había numerosos indicadores de la importancia que se le otorgaba a la formación de técnicos pero, por otra, el Proyecto de reforma del sistema educativo nacional de 1968 - y sus sucedáneos, que culminaron en Plan nacional de desarrollo y seguridad (1971-1975)— fue obra exclusiva de los ministros de educación y sus asesores, sin la consulta a los funcionarios del CONET. Mientras que para los ideólogos de la Reforma las características y objetivos asignados al nivel intermedio y al nivel medio eran las claves para la formación de recursos humanos requeridos por el mercado de trabajo, los funcionarios del CONET sostenían que la educación vocacional y práctica del nivel intermedio «obligatorio» no era homologable al ciclo básico que sostenía el organismo. Tampoco lo era el ciclo superior al bachillerato, que implicaba la reducción de la carrera de técnico a la de bachiller técnico. Para autoridades, supervisores e inspectores del CONET la Reforma no conducía, y hasta desviaba, el alcance de los objetivos de la educación técnica. Percibían que se confundía la educación vocacional y práctica con la educación técnica dado que se postergaba la capacitación laboral a instancias de educación no obligatorias. A la vez que se otorgaba gran importancia a la educación técnica en los discursos oficiales, los contenidos específicos intentaron ser excluidos del currículo de la educación en vías de reforma y fueron parciales las soluciones a las demandas de vacantes.

La planificación de la educación media no produjo cambios concretos capaces de responder a los problemas de la educación técnica. El proceso de implementación de la microexperiencias de la Reforma tuvo una mínima llegada a las escuelas medias del CONET. Las acciones en favor de la regionalización de la educación, para que responda con eficacia a las actividades económicas regionales fueron ineficaces. Las 
propuestas de enseñanza, en términos generales, no fueron actualizadas. La cantidad y las especialidades de los cursos nocturnos de formación profesional de operarios, no obstante, crecieron significativamente. A través de estas instancias, se intentó estimular la educación permanente y se dio respuesta a las demandas del mercado de trabajo. Las respuestas diseñadas para afrontar el crecimiento de la matrícula fueron paliativas, condicionadas por problemas presupuestarios. Pese a la apertura de nuevos ciclos y ENET, estos no resultaron suficientes y se dieron estrategias que afectaron los trayectos educacionales de los alumnos.

En suma, el contraste entre discursos y acciones permite advertir que las ideas fuerza que marcaron el período no llegaron a concretarse y que las acciones en favor del fortalecimiento la educación técnica nacional fueron escasas e ineficientes, más si se compara la cantidad de establecimientos existentes al final del período, con los ciclos básicos del bachillerato.

\section{Nota sobre la autora}

Gabriela A. D'Ascanio es profesora en Ciencias de la Educación por la Universidad Nacional de Rosario y doctoranda del Doctorado en Humanidades con mención en Ciencias de la Educación de la Universidad Nacional de Rosario. Becaria doctoral del Consejo Nacional de Investigaciones Científicas y Técnicas (CONICET) (2017 y continúa). Jefe de trabajos prácticos de la Cátedra Historia Socio-Política del Sistema Educativo Argentino del Ciclo de Formación Docente de la Escuela de Ciencias de la Educación, Facultad de Humanidades y Artes, Universidad Nacional de Rosario. Autora de los artículos «El impuesto para la educación técnica durante la última dictadura cívico militar Argentina (1976-1983)» (Revista Folia Histórica del Nordeste - ISSN: 0325-8238 e-ISSN: 2525-1627) http://dx.doi.org/10.30972/fhn.0415161; y, «Marchas y contramarchas de la educación técnica durante el tercer gobierno peronista (1973-1976)» (Revista Cadernos de História da Educação - ISSN: 19827806). Autora de las reseñas «Reseña: Ascolani, Adrián y Gutiérrez, Talía (coord.). Agro y político en Argentina. Desarrollismo, reforma agraria y contrarevolución, 1955-1976. Buenos Aires, CICCUS, 2020» (Revista Estudios Rurales - ISSN: 2250-4001); y, «Reseña: Fiorucci, F. \& Rodríguez, L. G. (Comp.) (2018). Intelectuales de la educación y el Estado: maestros, 
médicos y arquitectos. Bernal: Universidad Nacional de Quilmes»(Revista IRICE - ISSN: 0327-392X - e-ISSN: 2618-4052).

\section{REFERENCIAS}

Aguiar, Liliana, Pilar Castiñeira y M. del Cármen Orrico. «La formación docente en contextos de reformas. Procesos histórico-políticos en la Jurisdicción Córdoba». Cuadernos de Educación. La Educación como Espacio Público, año 2, n.o 2. (2002): 51-63.

Ascolani, Adrián y Talía Gutiérrez. «Introducción». En Agro y política en Argentina. Tomo III. Desarrollismo, reforma agraria y contrarrevolución, 19551976, editado por Adrián Ascolani y Talía Gutiérrez, 3-17. Bs. As.: Ciccus, 2020.

Bellini, Claudio. «Controversias y oscilaciones de la política industrial: de Perón a Frondizi». En Estudios sobre la industria argentina, editado por Marcelo Rougier, 117-162. Bs. As.: Lenguaje claro, 2013.

Bonavena, Pablo. "La lucha de los estudiantes de las Escuelas Técnicas contra la Ley Fantasma». X Jornadas de Sociología, Facultad de Ciencias Sociales, Universidad de Buenos Aires (2013). http://www.aacademica.org/000038/301

Cavarozzi, Marcelo. «Autoritarismo y democracia, 1955-1983». En La sociedad y el Estado en el desarrollo de la Argentina moderna, editado por Torcuato S. Di Tella y Cristina Lucchini, 201-248. Bs. As.: Biblios, 1999.

Fiszebein, Martín. «Crecimiento desbalanceado y estructura productiva desequilibrada en Argentina (1945-1976): problemas e ideas del modelo industrial en retrospectiva». En Estudios sobre la industria argentina, editado por Marcelo Rougier, 49-74. Bs. As.: Lenguaje claro, 2013.

Gallart, María Antonia. La escuela técnica industrial: un modelo para armar. Montevideo: OIT/Cinterfor, 2006.

García, Natalia. «Visiones clandestinas, prácticas autoritarias y reforma educativa en Santa Fe (Argentina, 1966-1973)». Espacio, Tiempo y Educación, vol. 5, n. 1 (2018): 159-180. doi: http://dx.doi.org/10.14516/ete.202

Luca, Romina de. «La Reforma educativa de Onganía. El tercer momento de una estrategia». Razón y Revolución, n. ${ }^{\circ} 15$ (2006): 165-182.

Martínez Paz, Fernando. El Sistema Educativo Nacional. Formación. Desarrollo. Crisis. Córdoba: UNC, 1980.

Munck, Ronaldo. «Movimiento obrero, economía y política en Argentina: 19551985». Estudios Sociológicos, vol. 13, n. 5 (1987): 87-109. 
Pineau, Pablo. «De zoológicos y carnavales: las interpretaciones sobre la Universidad Obrera». En Estudios de Historia de la Educación durante el Primer Peronismo (1943-1955), editado por Héctor Cucuzza, 205-228. Bs. As.: Libros del Riel, 1997.

Pineau, Pablo. «La vergüenza de haber sido y el dolor de ya no ser. Los avatares de la educación técnica entre 1955 y $1983 »$. En Dictaduras y utopías en la historia reciente de la educación argentina (1955-1983), editado por Adriana Puiggrós, 379-402. Bs. As. Galerna, 1997.

Pineau, Pablo. Sindicatos, estado y educación técnica (1936-1968). Bs. As.: CEAL, 1991.

Puiggrós, Adriana. Imperialismo y Educación en América Latina. México: Nueva Imagen, 1980.

Riz, Liliana de. La política en suspenso 1966/1976. Bs. As.: Paidós, 2000.

Rodríguez, Laura. "Los católicos desarrollistas en Argentina. Educación y planeamiento en los años de 1960». Diálogos, vol. 17, n. 1 (2013): 155-184. http://dx.doi.org/10.4025/dialogos.v17i1.723

San Román, Pablo de. «Los militares y la idea de progreso: la utopía modernizadora de la Revolución argentina (1966-1971)». Documentos de Trabajo IELAT, n. 31 (2011): 1-32.

Sosa, Mariana. «Desarrollo industrial y educación técnica: una estrecha relación. El caso Argentino». Revista Latino-Americana de Historia, vol. 5, n. ${ }^{\circ} 15$ (2016): 174-195.

Suasnábar, Claudio. «Desarrollismo, sociología científica y planeamiento de la educación: el debate intelectual de los sesenta». En Universidad e Intelectuales. Educación y política en la Argentina (1955-1976), editado por Claudio Suasnábar, 29-46. Bs. As.: Edit. FLACSO/Manantial, 2004.

Suasnábar, Claudio. Intelectuales, exilios y educación. Producción intelectual e innovaciones teóricas en educación durante la última dictadura. Rosario: ProHistoria, 2013.

Taroncher Padilla, Miguel A. «El proceso de inestabilidad político institucional en la Argentina: el golpe de estado de 1966 y algunos aspectos de la opinión pública». Estudios Ibero-Americanos, vol. 38, n. 1, (2012): 45-61.

Tedesco, Juan Carlos. Industrialización y Educación en Argentina. UNESCO, Programa Desarrollo y Educación en América Latina y el Caribe, 1977.

Villaverde, Aníbal. "La escuela intermedia en la accidentada evolución de la reforma educativa». En La Escuela Intermedia en debate, editado por Alfredo Bravo y Aníbal Villaverde, 231-260. Bs. As.: Ed. Humanitas, 1971.

Wiñar, David. Educación Técnica y evolución social en Argentina. Bs. As: Comisión Económica para América Latina, 1981. 